


\title{
Formação profissional em diálogo com agricultura familiar mediada pela extensão universitária
}

\author{
Professional education in dialogue with family agriculture mediated by university \\ extension
}

José Ribeiro da Silva

Professor do Instituto Federal de Alagoas, Campus Batalha Doutorando em Extensão Rural na Universidade Federal de Santa Maria jose.ribeiro@ifal.edu.br

\section{RESUMO}

O presente estudo teve como objetivo analisar os impactos da extensão universitária na formação profissional de estudantes envolvidos no contexto da agricultura familiar. Foi utilizado como caso de análise um projeto desenvolvido pelo Colégio Politécnico da Universidade Federal de Santa Maria que aproxima estudantes do contexto da agricultura familiar na região central do Rio Grande do Sul. Os participantes do projeto passaram a interagir com a realidade dos agricultores, identificando suas limitações e potencialidades e construindo estratégias de produção sustentável, possibilitando maior qualidade em seus produtos e acesso aos mercados locais. O método utilizado para a coleta de dados foi o grupo focal, envolvendo três estudantes e dois servidores participantes do projeto. Como resultado, foi percebido que, a partir do contato com os agricultores, estes alunos passaram a ter mais segurança na aplicação de conhecimentos técnicos e, com isso, passaram a adequar tecnologias aprendidas em sala de aula à realidade dos agricultores. Além disso, desenvolveram habilidades de comunicação e mobilização voltadas para a resolução de problemas enfrentados pela agricultura familiar. O projeto despertou nesses alunos comportamentos como cooperação, empatia, solidariedade e justiça. Concluiu-se que a aproximação entre estudantes e agricultores familiares, mediada pela extensão universitária, vem contribuindo para a formação de profissionais qualificados para o mundo do trabalho e sensiveis aos contextos sociais e econômicos que envolvem a agricultura familiar da região.

Palavras-chave: Economia solidária, Agroecologia, Desenvolvimento rural, Sustentabilidade.

\section{ABSTRACT}

The present study aimed to identify the impacts of university extension on the professional education of students involved in family farming. The study case focuses on a project developed by the Polytechnical School at the Federal University of Santa Maria, Rio Grande do Sul, Brazil (Colégio Politécnico da Universidade Federal de Santa Maria) that approximates students to the context of family farming in the central region of Rio Grande do Sul. The participants in the project were introduced to the reality of farmers, identified their limitations and potentialities and built sustainable production strategies, which allows better quality of products and access to local markets. The method of the investigation consisted of a focal group involving three students and two technicians in the project. As a result, it was verified that the students in the project became more secure in the application of technical knowledge and were able to adapt the technologies learned in their classes to the reality of family farming. In addition, they developed communication and mobilization skills to solve problems faced by family farmers. The project also allowed students to develop their sense of cooperation, empathy, solidarity, and justice. Approximating students and farmers with the mediation of university extension activities contributes to the education of qualified professionals for the market. It also make them sensitive to social and economic contexts surrounding family farming in the region.

Keywords: Solidarity economy, Agroecology, Rural development, Sustainability. 


\section{INTRODUÇÃO}

Nos últimos anos, os debates sobre a curricularização da extensão universitária vêm ganhando cada vez mais espaço no meio acadêmico, fato que fortalece as capacidades institucionais na dinamização do ensino e na inspiração de programas e projetos de pesquisa. A interdependência dos três segmentos (extensão, ensino e pesquisa) busca consolidar o tripé estratégico do ensino superior no Brasil, aproximando a universidade dos contextos e demandas sociais, econômicas, ambientais e culturais nos territórios onde estão inseridas.

De acordo com Mussoi e Lenzi (2015), a extensão universitária foi, por algum tempo, suprimida pela importância dada à pesquisa e ao ensino. Para esses autores, as consequências foram marcantes dentro dos projetos político-pedagógicos das universidades, destacando, como principal problema, a hierarquização de importância em que as dimensões de pesquisa e ensino foram e ainda são entendidas como autossuficientes.

O tratamento dado à extensão universitária como algo de importância inferior foi assumido pelo viés difusionista, com a finalidade de levar até a sociedade os resultados das pesquisas produzidas dentro da universidade, muitas vezes descontextualizadas e não condizentes com as verdadeiras demandas sociais.

Essa visão começou a ser superada no início dos anos 2000, quando a extensão universitária passou a ser considerada como um instrumento de inter-relações entre a universidade e a sociedade o que vem proporcionando a democratização, a produção e a reprodução de conhecimentos por meio da troca de saberes com as comunidades (Fórum de Pró-Reitores das Instituições Públicas de Educação Superior Brasileiras [FORPROEX], 2012).

Designar à extensão universitária o papel estratégico para encurtar o distanciamento entre universidade e sociedade é um reconhecimento da sua trajetória de integração com os tecidos sociais, iniciado a partir do Manifesto de Córdoba, em 1918. A esse respeito, Gadotti (2017, p. 1) afirma que "se existe, na história da universidade brasileira, uma área que se preocupou em manter vínculos com a sociedade é, certamente, a extensão, mesmo tendo enfrentado enormes resistências, em face do elitismo que marca a educação brasileira".

Diante desses desafios, cabe destacar a importância da Política Nacional de Extensão Universitária elaborada de forma participativa no âmbito do FORPROEX e de universidades, aprovada em 2012, durante o XXXI Encontro Nacional do FORPROEX em Manaus (AM). Esta política, em seu primeiro objetivo, destaca o compromisso que deverá ser assumido pela extensão universitária com o processo de dinamização acadêmica, propondo "reafirmar a Extensão Universitária como processo acadêmico definido e efetivado em função das exigências da realidade, além de indispensável na formação do estudante, na 
qualificação do professor e no intercâmbio com a sociedade" (FORPROEX, 2012, p. 9).

Essa perspectiva estabelece um reconhecimento do papel da extensão como estratégico para a dinamização acadêmica. Articulada ao ensino e à pesquisa, a extensão constitui a base do ensino superior no Brasil, tendo como função possibilitar aos jovens uma "formação integral, ética e humanística, tão necessárias para os dias atuais" (Almeida, 2015, p. 57).

Ainda no que diz respeito às contribuições da extensão universitária na formação dos estudantes, Costa, Baiotto \& Garcez (2013) argumentam que a relação extramuros que aproxima a universidade da sociedade possibilita ao estudante participante de projetos de extensão a tomada de consciência quanto ao seu papel como profissional e cidadão, tornando-o mais sensivel aos problemas sociais.

Nesse sentido, compreender o processo de formação profissional e cidadã, tendo como centro de análise as ações extensionistas, consiste no desafio deste trabalho, que apresenta o seguinte problema de pesquisa: como a aproximação entre estudantes e agricultores familiares, mediada pela extensão universitária, vem contribuindo para a formação profissional?

Diante desse questionamento, o presente estudo teve como objetivo analisar os impactos da extensão universitária na formação profissional de estudantes envolvidos no contexto da agricultura familiar. Tomou-se como caso o projeto Polifeira da agricultura familiar, desenvolvido pelo Colégio Politécnico da Universidade Federal de Santa Maria (UFSM). Optou-se por essa iniciativa por ela estar ligada principalmente aos cursos técnicos e tecnológicos na área de ciências agrárias, e também por estabelecer uma conexão com agricultores familiares da região central do Rio Grande do Sul.

O Polifeira teve início em 2017 como projeto de extensão do Colégio Politécnico da UFSM. Foi inspirado em um projeto anterior, iniciado em 2014, intitulado Promoção dos circuitos curtos de comercialização e consumo de frutas e hortaliças no município de Santiago-RS. O projeto iniciado em 2014 contribuiu com a construção do sistema agroalimentar local, possibilitando ao município de Santiago-RS o reconhecimento de suas capacidades de produzir parte dos alimentos para consumo interno, assim como de enfrentamento dos dilemas da agricultura familiar por meio do acesso aos mercados locais (UFSM, 2017).

Segundo informações do Relatório de Atividades do Projeto, de 2019, as atividades eram conduzidas por quatro bolsistas dos cursos técnicos e superior do Colégio Politécnico, e dois servidores, sendo um docente e um técnico administrativo. Essa foi considerada a equipe formal do projeto em dezembro de 2019. No entanto, desde o seu início, em 2017, o Polifeira contou com a participação de dezoito alunos bolsistas ou voluntários, sendo oito de cursos técnicos, seis de graduação e quatro de pós-graduação. Quanto à participação de servidores, o projeto envolveu, desde 2017, dezoito servidores, sendo três técnicos administrativos em educação e quinze docentes. 
Na feira, é possivel encontrar frutas e hortaliças frescas, além de flores, plantas ornamentais e medicinais produzidas de forma sustentável. Também é possivel encontrar alimentos processados artesanalmente a partir de matérias-primas produzidas pelos próprios agricultores, como condimentos, sucos, doces, geleias, salgados, bolos, tortas, pães, biscoitos, massas, embutidos e produtos lácteos, entre outros.

A feira, que acontece duas vezes por semana nas instalações da universidade, é apenas uma das etapas do projeto, que envolve, ainda, outras atividades, como o acompanhamento produtivo dos agricultores familiares em suas propriedades, apoio à comercialização na feira e à promoção de estratégias de mercado, gestão da qualidade dos produtos nela comercializados, assim como análises laboratoriais para identificar características sanitárias dos produtos. Essas atividades são realizadas pelos alunos bolsistas e voluntários, com o suporte de professores e técnicos do Colégio Politécnico.

\section{METODOLOGIA}

De acordo com os procedimentos técnicos adotados, a pesquisa pode ser caracterizada como estudo de caso. Essa definição tomou como base os argumentos de Gil (2002), quando define esse tipo de método como essencial para explorar situações reais cujos limites não estão claramente definidos, buscando preservar o caráter unitário do objeto estudado. Para a coleta de dados, foi utilizado o grupo focal.

Participaram dessa atividade três alunos, sendo dois bolsistas e um voluntário do projeto, que, na apresentação dos resultados, serão identificados como Aluno 1, Aluno 2 e Aluno 3. Também participaram dessa atividade dois membros da coordenação do projeto, identificados como Servidor 1 e Servidor 2.

Para o grupo focal, não foi estabelecido um roteiro; apenas foi solicitado aos participantes que relatassem suas experiências com o projeto. A partir desse ponto, a discussão passou a ser mediada com o intuito de se buscar um direcionamento que auxiliasse no levantamento de informações relacionadas aos impactos do projeto na formação profissional.

A discussão foi registrada por meio de gravador de voz, sendo transcrita posteriormente em sua totalidade, considerando-se a autorização informal dos participantes antes do início dos debates. O áudio original, assim como o texto transcrito, encontram-se sob a guarda do pesquisador, que assume a responsabilidade pelo devido sigilo e integralidade das informações apresentadas.

\section{RESULTADOS E DISCUSSÃO}

A participação dos alunos no projeto, como bolsistas ou voluntários, consiste na realização de atividades de orientação no planejamento produtivo, beneficiamento, qualidade dos produtos, mercado local, designer de 
embalagens, desenvolvimento de novos produtos, comercialização e produção sustentável. Além disso, os estudantes desenvolvem atividades relacionadas à gestão e ao monitoramento do projeto, como registros, organização, suporte à comercialização na feira, coleta de produtos para análises, levantamento de dados para avaliação e divulgação da feira nas páginas e redes sociais do Politécnico e da Universidade, assim como o gerenciamento de um site do próprio projeto. Estes processos geram um impacto significativo na formação profissional, tanto nos cursos do Politécnico como na UFSM.

De acordo com um dos servidores envolvidos na coordenação do projeto, o contato com a agricultura familiar representa o contato com a realidade do campo como ela realmente é. Isso faz com que os alunos envolvidos passem a articular seus conhecimentos acadêmicos no intuito de solucionar problemas e, com isso, ter um diferencial em seu aprendizado.

Estamos trabalhando com a problemática como ela acontece, [...] in loco. As particularidades de cada propriedade, eles (os alunos) vão através daquele conhecimento que eles adquirem dentro da academia (universidade). No campo (propriedades rurais), eles têm que achar alternativas para que aquilo funcione, da melhor forma para aquele agricultor (Servidor 2).

Para os alunos, a participação no projeto thes deu mais segurança nos diálogos com os agricultores nos momentos de orientação técnica. Essa segurança foi proporcionada pelo maior contato com a técnica, pois, antes de levarem as informações até os agricultores, eles fazem um estudo detalhado das tecnologias a serem fomentadas. Por outro lado, a aproximação e o diálogo com os agricultores fazem com que os alunos percebam suas demandas, estimulando a busca por resultados de pesquisas e manuais de tecnologia mais indicados para cada agricultor. Em muitos casos, os alunos são estimulados pelos próprios agricultores a buscarem uma adequação dessas tecnologias. Eles colaboram muito com isso. Eles são muito imperativos, eles me ajudam bastante. Normalmente o incentivo parte deles, e daí eu tento englobar eles, buscar tecnologias, fechar alguma coisa com eles, daí eles me ajudam muito. Eu tenho algumas dificuldades, questão de maquinário, alguma coisa assim, mas a gente sempre consegue (Aluno 1).

É possivel perceber na fala do Aluno 1 uma sensibilidade para conceber as suas limitações como profissional em formação, ao mesmo tempo que encontra, nas demandas apresentadas pelos agricultores, instrumentos de motivação para o enfrentamento dessas limitações.

Outro aspecto diz respeito à forma como os alunos percebem o papel da tecnologia aprendida durante os cursos, assim como sua aplicabilidade nas mais diversas realidades que envolvem o espaço rural. Eles passaram a compreender que as tecnologias precisam ser reeditadas, partindo dos processos mais gerais para as demandas mais específicas. Nesse caso, aquelas relacionadas às particularidades da agricultura familiar. 
Essa perspectiva de adequação tecnológica parte das constantes reflexões promovidas pelo projeto no que diz respeito à forma de vida, às tradições e às limitações ligadas à agricultura familiar. Esse fato contribui para que os alunos percebam as diferenças de concepção e demandas de tecnologias entre a produção artesanal, característica da maioria dos agricultores familiares, e a produção em escala, mais adequada à agricultura patronal e ao monocultivo.

Além disso, os estudantes destacam como importante a identificação de possibilidades de se produzir com qualidade sem perder características relacionadas ao artesanal, agregando valor aos produtos da agricultura familiar, o que passa a ser visto pelos alunos como um tipo de missão do projeto.

Eu acho assim, [...] por se tratar de agricultura familiar, eles têm muito aquele pensamento que é o certo [...], que inclusive é uma das nossas missões. [...] é manter o artesanal [...], é aquela receita, a cultura lá da família [...] (Aluno 2).

Para esses alunos, a produção artesanal é caracterizada pelos elementos culturais no modo de fazer, assim como os instrumentos utilizados no processo, que agregam um valor simbólico a esses produtos, como apresentado pelo Aluno 1: "Tanto a cultura quanto o modo de fazer né?! A cozinha dele, o fogão a lenha, uma panela de ferro, alguma coisa assim, o valor simbólico que tem".

Para outro aluno, a participação no projeto representou uma mudança de paradigmas no que diz respeito à visão que tinha sobre a agricultura. De acordo com esse aluno, "a família do meu pai, principalmente, a base financeira dela é a agricultura. Só que é uma agricultura maior. Produtores de soja, de leite. E sobre a visão que eu tinha, até antes de entrar, era uma visão muito mais financeira [...]" (Aluno 3).

Para ele, a participação no projeto contribuiu para que sua visão fosse ampliada, passando a considerar a realidade social, a produção artesanal desses agricultores, sem perder de vista os impactos econômicos já percebidos no cotidiano dos agricultores envolvidos no projeto.

Outra contribuição do Polifeira diz respeito ao incentivo à cooperação. 0 Aluno 2 relata que, no momento em que alguém da equipe do projeto está com alguma dificuldade, outros membros se mobilizam em torno do problema, propondo ideias ou instrumentos na tentativa de solucioná-lo.

A cooperação da equipe é refletida na relação entre os agricultores envolvidos diretamente no projeto. Esses são estimulados a cooperar a partir da própria dinâmica de comercialização na feira, onde foram criadas estratégias que inibem a concorrência entre eles. Além disso, o incentivo é dado pelo projeto por meio da criação de pequenas redes de compra e venda entre os próprios agricultores da feira. Isso é possivel pelo fato de que, para os agricultores, só é permitido comercializar os produtos que eles produzem em suas propriedades, critério que veda a atuação deles como atravessadores.

Nesse sentido, os alunos também atuam na articulação dessas redes, nas quais, por exemplo, o agricultor que faz a torta de morangos é estimulado a 
comprar o morango de outro agricultor envolvido. A agricultora que faz salgado pra vender em sua barraca adquire o queijo do agricultor que produz e comercializa produtos lácteos. Além disso, se os agricultores não produzem determinados produtos e precisam consumi-los, estes são sensibilizados a adquirir da própria Polifeira, em vez de adquirir em outras feiras ou mercados onde a procedência do produto é desconhecida.

Na relação e nos diálogos entre agricultores e alunos, é possivel perceber o despertar de estratégias a partir de oportunidades não percebidas anteriormente. Em muitos casos, os agricultores são estimulados pelos alunos a refletirem sobre os desafios existentes. Isso resulta, na maioria das vezes, em redimensionamento ou mudança de estratégias de produção, beneficiamento ou comercialização.

Como exemplo, foi apresentado o caso de uma agricultora que desenvolveu uma cuca de morango que teve uma boa aceitação pelos consumidores. Por algum motivo, ela deixou de trazer a cuca regularmente, causando frustração nos consumidores, que deixavam de comprar quando ela trazia nas feiras seguintes. Essa agricultora foi orientada a manter a regularidade em respeito ao consumidor. Outro exemplo pôde ser apresentado pelo Aluno 1.

Tudo começou porque ela queria vender pastel. Dai a gente falou não! Traz um sanduiche. Dai o sanduiche ela trouxe uma vez e não vendeu. Ai um dia eu disse: mas se nós prensarmos o sanduiche? Uma torrada colonial? Vamos lá falar com ela. Dai na outra semana ela já começou e foi a sensação do inverno (Aluno 1).

Percebe-se, nessas informações, a importância do diálogo e da relação de confiança entre os agricultores e os estudantes. Parte-se dos problemas cujas causas são identificadas e analisadas de forma dialógica, sendo, na maioria das vezes, solucionados.

Um dos grandes desafios enfrentados pelos extensionistas rurais e também pelos bolsistas de projetos de extensão universitária que envolvem a agricultura familiar diz respeito à inovação de suas práticas ou à adoção de novas tecnologias. Nesse sentido, os alunos buscam estimular a inovação a partir de elementos da própria cultura ou das tradições dos agricultores.

O relato de uma dessas estratégias foi apresentado pelo Aluno 1. Segundo esse aluno, a partir de um diálogo estabelecido com um agricultor que não sabia o que fazer com a mandioca produzida, chegaram à definição de estratégias para viabilizar o processamento e comercialização da mandioca. A busca de estratégias partiu da reflexão sobre o que já existia como derivado de mandioca e o que ainda não existia. Como resultado, surgiu a ideia de se produzir um pastel vegano, tendo como base a massa da mandioca. Essa estratégia solucionou duas demandas: gerou um produto diferenciado e com maior valor agregado a partir de uma matéria-prima que, na maioria das vezes, era comercializada in natura ou semiprocessada. Por outro lado, atendeu um grupo 
de consumidores veganos, público que vem crescendo dentro da universidade e na sociedade como um todo.

Esse aspecto revela o desenvolvimento de habilidades de comunicação numa perspectiva dialógica em que estudantes e agricultores identificam, analisam e atuam em torno das limitações no intuito de solucionar os problemas, utilizando como estratégia a junção dos saberes populares e acadêmicos na busca de soluções viáveis.

Chama atenção, também, nesse projeto, o despertar, nos alunos, do comportamento de empatia em relação aos agricultores familiares. Isso pode ser percebido no relato do Aluno 2 quando entrou em defesa dos agricultores em situações que sinalizavam para uma relação injusta do consumidor quanto ao agricultor.

O caso envolveu um consumidor que estava reclamando do preço cobrado pelos agricultores em seus produtos. O aluno se sentiu na obrigação de esclarecer para aquele consumidor que o preço daqueles produtos estava igual ao preço de mercado. Esclareceu, ainda, que tudo aquilo era produzido pelas mãos daqueles agricultores, que ele, como bolsista do projeto, conhecia cada um deles, visitava suas propriedades e tinha os laudos das análises laboratoriais certificando que aqueles produtos eram obtidos sem agrotóxicos.

\begin{abstract}
Uma consumidora chega e pergunta: Quanto que tá a alface? Aí o feirante responde. Daí a cliente diz: Mas tá caro né? Ai eu disse: não, não tá caro não! Não tá caro mesmo! Sabe por que não tá caro? Porque essa alface aqui, é o seu Jorge que planta com a mão dele! Foi a mesma mãozinha que arrancou e trouxe aqui pra senhora. Não tá caro não. Essa alface do seu Jorge não tem veneno. E não tem veneno porque sou eu que dou a recomendação pra ele, se a senhora quiser eu tenho um laudo para mostrar (Aluno 2).
\end{abstract}

Essa postura do aluno, além de afirmar sua empatia com a realidade dos agricultores familiares, revela o seu papel como profissional e cidadão na valorização da produção artesanal, local e sustentável. Mostra ainda que o reconhecimento da justiça e da solidariedade nas relações de compra e venda entre agricultores e consumidores deve ser construido e/ou preservado, fortalecendo as relações sociais e de confiança.

Mesmo considerando a importância do artesanal e assumindo, empaticamente, em alguns momentos, os dilemas dos agricultores como deles, esses alunos buscam despertar nos agricultores novos comportamentos diante da realidade do mercado em que eles estão inseridos.

Só que nós, enquanto alunos, qual que é o nosso trabalho? É também fazer eles se qualificarem e se atualizarem [..... A gente tira eles lá do lugarzinho deles pra botar eles dentro da universidade, mas com essa condição: [...] vocês não podem ficar dentro da zona de conforto de vocês. Vocês tão dentro de uma universidade então vocês têm que ter outra coisa pra oferecer. E têm, não são todos, não é tão fácil, não é tão simples. Só que dai aquela coisa assim, tu sabe que a grama do vizinho é sempre mais verde né? Aí a banquinha do lado vê que deu 
certo, que o vizinho tá ganhando dinheiro com aquilo. Querendo ou não, aquilo é um estímulo pra ele tentar ir atrás de uma coisa diferente [...]. E isso é outra coisa que nos estimula muito porque a gente não deixa eles repetirem (Aluno 2).

Nessas reflexões, os alunos também contribuem para que os agricultores valorizem suas próprias potencialidades, que ficam, às vezes, adormecidas e que podem contribuir de forma significativa com transformações em seu cotidiano.

Às vezes eles investem e eles não sabem como ter o retorno do investimento que eles fazem. Uma agricultora foi fazer um curso em Caxias do Sul. Ficou uma semana lá, fazendo cuca, fazendo pão, brioche, né! Umas coisas assim. Para ela colocar na banca dela da feira. Foi a Emater quem levou eles. E aí ela disse: eu tenho o pãozinho pra fazer né? E eu disse: então, vamos fazer uma torrada, ai os outros itens tu compra daqui e aí é só o salame e o queijo e o pão que é ela que faz. Ai foi sucesso assim. O pessoal aderiu muito né, e tem muito aquela coisa, tipo de casa de mãe né? Onde que a gente vai comer uma torrada com salame, queijo né? Não tem. (Aluno 2).

Os alunos também se utilizam de estratégias de pesquisa como forma de subsidiar os agricultores na busca de potencializar e alinhar as suas ofertas com as necessidades e demandas do consumidor. Um dos alunos descreveu um pouco de sua pesquisa realizada com os consumidores da Polifeira, destacando como os resultados dessa pesquisa podem contribuir com melhorias no processo de produção e comercialização.

O que tu acha que pode ser melhor, é o cheiro? É o sabor? É a cor? A textura? Tu acha que tem que ser mais doce? Salgado? Alguma coisa assim. Eles avaliaram também a banca, a questão de como o feirante se porta, se tá sempre uniformizado. A questão da unha né? Toda parte de higiene do feirante da banca eles avaliaram também. Dai eu peguei os resultados e levei pros feirantes. Mostrei pra eles, olhem eles acham isso e isso de ti, o que que tu acha? Vamos melhorar, vamos fazer tal coisa. Grande parte deles aceitou tranquilo (Aluno 1).

O comportamento de resistência, marcante na maioria dos agricultores, é encarado pelos alunos como uma forma de comodismo e sua superação é estimulada no processo.

A agricultora trouxe um dia torrada né, trouxe uma e à tarde eu comprei, passei por um professor e eu disse: ó, come uma torrada ali, ai o professor foi lá e comprou e nós tiramos foto. Naquela tarde, ela só vendeu essas duas torradas pra mim e pra ele. Ai no final da feira ela me disse: eu não vou trazer mais. Não vendeu. Eu disse: mas tchê, tu recém trouxe hoje e nós recém tiramos fotos, recém vamos fazer a propaganda, insiste um pouquinho mais. Nem todo mundo já passou pela feira e viu que tu tem torrada. Isso não é da noite pro dia. Ai tá, tem vezes que tu tem que se impor mesmo. A ideia a gente tem de monte, mas às vezes nada vai adiante por falta de persistência 
deles né. Aí ela trouxe de novo e a gente fez uma publicação que, tipo, teve muita visualização e aí começou! Ai ela disse: não, eles estão realmente nos ajudando né. E aí tem essa questão que a gente tá tentando educar eles pra eles pararem de pensar na feira apenas como um ponto comercial né. Por que o que eles fazem aqui é muito maior do que simplesmente vir vender. Mas, pra gente ter acesso a eles, a gente sempre tem que partir do principio de ganhar dinheiro, querendo ou não (Aluno 2).

Por outro lado, algumas exceções a essa resistência foram percebidas, pois alguns agricultores estão sempre buscando inovar, criar produtos novos ou diferenciados e que sempre estão apresentando demandas. "Como sempre há exceções, tem outros que estão sempre buscando inovar, sempre buscando fazer alguma coisa nova. Daí esses eu junto né, eu colo neles né, porque ali dá alguma coisa nova" (Aluno 3).

Do ponto de vista acadêmico, a extensão desenvolvida pelo projeto tem se destacado como uma estratégia inovadora para dinamização do espaço acadêmico, atraindo as ações do ensino e da pesquisa, buscando romper com a cultura predominante nas universidades brasileiras, onde a extensão esteve sempre pautada como apêndice das ações de ensino e da pesquisa. Essa perspectiva se aproxima dos argumentos apresentados por Almeida (2015), quando esse afirma que o reconhecimento do papel da extensão universitária, articulada ao ensino e à pesquisa, possibilitam uma formação integral, ética e humanistica.

Ao participar do projeto, os alunos passam a se relacionar com experiências reais que envolvem múltiplos campos de saberes, promovidos pela dinâmica e pelas vivências dos agricultores familiares, com os quais mantiveram contato, e também com os colegas que estão sempre discutindo tecnologias, contextos, desafios e estratégias. Essa perspectiva corrobora com os argumentos de Costa, Baiotto \& Garcez (2013) quando argumentam que os alunos que participam de projetos de extensão tomam consciência de seu papel como profissional e cidadão, tornando-se mais sensiveis aos problemas sociais.

O projeto promove, ainda, o envolvimento de outros cursos ofertados pela UFSM, como: comunicação, educação, biologia, gestão ambiental, terapia ocupacional, química, entre outros. Isso demonstra não só a interdisciplinaridade como também a interprofissionalidade, duas das diretrizes da extensão universitária definidas pelo FORPROEX (2012), apresentadas na Política Nacional de Extensão Universitária.

Portanto, o projeto busca romper com a visão da extensão como apêndice das dimensões da pesquisa e do ensino nas universidades, como criticado por Mussoi e Lenzi (2015). O projeto consolida um processo acadêmico no qual as dimensões do ensino, da pesquisa e da extensão interagem e complementamse, definindo várias possibilidades de ensino-aprendizagem. 


\section{CONCLUSÕES}

A interação entre instituição e sociedade, mediada pela extensão, contribui para que os alunos passem a ter mais domínio das técnicas inerentes à sua profissão. Ao mesmo tempo, torna-os mais sensiveis aos desafios e particularidades dos agricultores familiares.

O contato direto e constante com os agricultores possibilitou aos estudantes o desenvolvimento de comportamentos importantes, como empatia, cooperação, justiça e solidariedade. Além disso, a identificação dos desafios e potencialidades desses agricultores estimulou o domínio dos padrões tecnológicos por parte dos estudantes, ao mesmo tempo que conduziu os padrões para uma adequação ou, até mesmo, para uma reelaboração dessas tecnologias, tornando-as mais apropriadas à realidade da agricultura familiar.

Diante disso, os impactos da interação entre estudantes e agricultores familiares, mediada pela extensão universitária, tendo como caso o projeto Polifeira, trouxeram contribuições significativas para a formação de profissionais sensiveis à realidade que envolve a agricultura familiar na região central do Rio Grande do Sul. No entanto, por se tratar de um único caso estudado, as análises não podem ser generalizadas, não sendo impedido seu uso como referência para inspirar outros estudos envolvendo outras instituições em outros contextos. 


\section{REFERÊNCIAS}

Almeida, L. P. (2015). A extensão universitária no Brasil: processos de aprendizagem a partir da experiência e do sentido. Revista Diversités Recherches et Terrains: Les universités latino-américaines aujourd'hui: expressions locales, DIRE, 7(1), 56-67. https://wwww.unilim.fr/dire/645http://epublications.unilim.fr/ revues/dire.

Costa, A. A. C.; Baiotto, C. R.; \& Garcez, S. B. B. (2013). Aprendizagem: o olhar da extensão. In Síveres, L. (org.). Extensão Universitária como principio de aprendizagem. Brasilia: Liber Livro, 61-80.

Fórum de Pró-Reitores das Instituições Públicas de Educação Superior Brasileiras. (2012). Política nacional de extensão universitária. Manaus, 66 p.

Gadotti, M. (2017). Extensão Universitária: para quê? São Paulo: Instituto Paulo Freire, 2017, 1-18. https://www.paulofreire.org/noticias/557-extensao-universitaria-para-que.

Gil, A. C. (2002). Como elaborar projetos de pesquisa. São Paulo: Atlas. ed. 4. 175p.

Mussoi, E. M.; Lenzi, L. H. C. (2015). Extensão Universitária: entre o continuísmo e a utopia. Revista Extensio. Florianópolis, 12(20), 103-122.

Universidade Federal de Santa Maria; Colégio Politécnico da Universidade Federal de Santa Maria. (2017). Projeto Polifeira do Agricultor na Universidade Federal de Santa Maria.

Data de submissão: 03/09/2020

Data de aceite: 02/02/2021 